\title{
Traumatismo Dento-alveolar: Tecidos Duros Dentários, Polpa e Processo Alveolar
}

\author{
Dento-Alveolar Trauma: Hard Dental Tissues, Polpa and Alveolar Process
}

Traumatismo Dentoalveolar: Tejidos Duros Dentarios, Pulpa y Proceso Alveolar

Erika Thaís Cruz da SILVA

Mestranda em Clínica Odontológica. Faculdade de Odontologia, Universidade de Pernambuco - FOP/UPE, 54.756-220, Camaragibe - PE, Brasil https://orcid.org/0000-0002-8475-7929 Marcelo Gadelha VASCONCELOS

Professor Doutor do Departamento de Odontologia da Universidade Estadual da Paraíba - UEPB, 58429-500, Araruna - PB, Brasil https://orcid.org/0000-0003-0396-553X Rodrigo Gadelha VASCONCELOS

Professor Doutor do Departamento de Odontologia da Universidade Estadual da Paraíba - UEPB, 58429-500, Araruna - PB, Brasil

\section{Resumo}

http://orcid.org/0000-0002-7890-8866

Introdução: As fraturas de coroa são as mais comuns de todas as lesões traumáticas dento-alveolares e acometem principalmente os dentes permanentes anteriores. São classificadas em fratura em esmalte, fratura em esmalte/dentina com ou sem exposição pulpar, fraturas coronorradiculares e fraturas radiculares. Objetivo: Realizar uma revisão de literatura acerca das lesões aos tecidos duros dos dentes e à polpa destacando desde aspectos clínicos e etiológicos ao tratamento. Além disso, também será descrita no presente estudo as fraturas do processo alveolar e aspectos referentes a imobilização dos traumatismos dento-alveolares que necessitam. Métodos: Realizou-se levantamento nas bases de dados PubMed/ Medline, Scielo e Google acadêmico, tendo como filtro publicações dos últimos 10 anos. A busca foi realizada com descritores previamente selecionados. A pesquisa ocorreu em 3 fases e os artigos foram incluídos obedecendo aos critérios de inclusão e exclusão. Resultados: As lesões aos tecidos duros dentários e à polpa podem classificar-se desde uma simples trinca de esmalte onde não há perda de tecido dentário até as fraturas radiculares em que o tratamento pode ser complexo e exigir até mesmo a imobilização do dente acometido. As fraturas do processo alveolar são frequentemente associadas aos traumatismos dentários e podem requerer uma abordagem mais complexa do que as fraturas mais simples. Conclusão As fraturas aos tecidos duros dentários e da polpa são as mais comumente encontradas dentro todas as lesões por traumatismo dentoalveolares. É importante que o profissional realize um adequado diagnóstico bem como o acompanhamento dessas lesões.

Descritores: Traumatismos Dentários; Diagnóstico; Terapêutica.

\section{Abstract}

Introduction: Crown fractures are the most common of all traumatic dento-alveolar injuries and mainly affect the anterior permanent teeth. They are classified as enamel fracture, enamel / dentin fracture with or without pulp exposure, coronary root fractures and root fractures. Objective: To carry out a literature review about injuries to the hard tissues of the teeth and pulp, highlighting from clinical and etiological aspects to treatment. In addition, in the present study, fractures of the alveolar process and aspects related to immobilization of the dento-alveolar traumas they need will also be described. Methods: A bibliographic search was performed in the PubMed / Medline, Scielo and Google academic databases, using publications from the last 10 years as a filter. The search was carried out with previously selected descriptors. The research took place in 3 phases and the articles were included according to the inclusion and exclusion criteria. Results: Lesions to dental hard tissues and pulp can be classified from a simple crack of enamel where there is no loss of dental tissue to root fractures where treatment can be complex and even require immobilization of the affected tooth. Fractures of the alveolar process are often associated with dental trauma and may require a more complex approach than simpler fractures. Conclusion Fractures of the dental and pulp hard tissues are the most commonly found within all injuries caused by dento-alveolar trauma. It is important that the professional performs an adequate diagnosis as well as monitoring these injuries.

Descriptors: Tooth Injuries; Diagnosis; Therapeutics.

\section{Resumen}

Introducción: Las fracturas de corona son las más comunes de todas las lesiones dentoalveolares traumáticas y afectan principalmente a los dientes permanentes anteriores. Se clasifican en fractura de esmalte, fractura de esmalte / dentina con o sin exposición pulpar, fracturas de raíz coronaria y fracturas de raíz. Objetivo: Realizar una revisión de la literatura sobre las lesiones de los tejidos duros de los dientes y la pulpa, destacando desde los aspectos clínicos y etiológicos hasta el tratamiento. Además, en el presente estudio también se describirán las fracturas del proceso alveolar y aspectos relacionados con la inmovilización del trauma dentoalveolar que es necesario describir. Métodos: Se realizó una búsqueda bibliográfica en las bases de datos académicas PubMed / Medline, Scielo y Google, utilizando como filtro publicaciones de los últimos 10 años. La búsqueda se realizó con descriptores previamente seleccionados. La investigación se desarrolló en 3 fases y los artículos se incluyeron según los criterios de inclusión y exclusión. Resultados: Las lesiones en los tejidos duros dentales y la pulpa pueden clasificarse desde una simple fisura del esmalte donde no hay pérdida de tejido dental hasta fracturas radiculares donde el tratamiento puede ser complejo e incluso requerir la inmovilización del diente afectado. Las fracturas del proceso alveolar a menudo se asocian con traumatismos dentales y pueden requerir un abordaje más complejo que las fracturas más simples. Conclusión Las fracturas de los tejidos duros dentarios y pulpares son las más comúnmente encontradas dentro de todas las lesiones causadas por traumatismos dentoalveolares. Es importante que el profesional realice un diagnóstico adecuado así como el seguimiento de estas lesiones.

Descriptores: Traumatismos de los Dientes; Diagnóstico; Terapéutica.

\section{INTRODUÇÃO}

As fraturas de coroa são mais as comuns de todas as lesões traumáticas dentoalveolares e acometem principalmente os dentes permanentes anteriores ${ }^{1}$. De acordo com Gerard et al. ${ }^{2}$ as fraturas coronárias dos incisivos permanentes representam $18 \%$ a $22 \%$ de todos os traumas dentais nos tecidos duros, dentre esses, 96\% acometem incisivos superiores.

Essas fraturas afetam principalmente crianças e adolescentes. Estima-se que cerca de um quarto da população com idade inferior a 18 anos apresente fratura coronária em dentes anteriores ${ }^{1}$. As principais causas são quedas, acidentes automobilísticos, violência física e 
atividades esportivas. Além disso, existem algumas características que quando presentes no indivíduo também podem atuar como fatores predisponentes, que são o overjet acentuado e a cobertura labial inadequada dos dentes superiores ${ }^{2}$.

Dentre essas lesões, as mais comumente encontradas são as fraturas em esmalte e esmalte/dentina ${ }^{1}$. No entanto, dentro da classificação das lesões tecidos duros dentários e da polpa ainda temos as fraturas em esmalte e dentina com ou sem exposição pulpar, fraturas coronorradiculares e fraturas radiculares. $O$ atendimento ao paciente com fratura dentária imediatamente após o acidente traumático é de suma importância, sobretudo nos casos em que há envolvimento dos tecidos pulpares.

Um dente anterior fraturado pode, muitas vezes, comprometer o estado psicológico do paciente acometido impedindo o seu sorriso; e de certa forma isso pode afetar o seu relacionamento social com os outros indivíduos. Além disso, pode trazer alterações nas funções normais do aparelho mastigatório como a dificuldade de mastigar e alterações na fonação ${ }^{3}$.

Em todas as lesões traumáticas dentoalveolares é importante estabelecer um adequado diagnóstico para que o tratamento seja efetivo e o prognóstico favorável. Restaurar dentes anteriores fraturados com uma estética e função adequada representa um desafio ao profissional. Porém, é possível obter sucesso clínico se dentista seguir corretamente os protocolos clínicos de atendimento ao paciente nessas situações ${ }^{2}$

Dessa forma, o presente estudo tem como objetivo realizar uma revisão de literatura acerca dos traumatismos dento-alveolares. Será abordado as lesões aos tecidos duros dos dentes e da polpa destacando desde aspectos clínicos e etiológicos ao tratamento. Além disso, também será descrita no presente estudo as fraturas do processo alveolar e aspectos referentes a imobilização dos traumatismos dento-alveolares que necessitam.

MATERIAL E MÉTODO

Este estudo caracterizou-se por uma busca bibliográfica na base de dados PubMed/ Medline, Scielo e Google acadêmico. Os descritores utilizados para busca foram Tooth Injuries; Diagnosis e Therapeutics.

A pesquisa ocorreu em três fases: 1) Busca nas bases de dados com os descritores selecionados; 2) Leitura dos resumos e definição dos artigos a serem incluídos;
3)Leitura dos artigos na íntegra e construção dos resultados.

Como critérios de inclusão, foram adotados os artigos escritos em inglês e português, aqueles que se enquadravam no enfoque do trabalho e os mais relevantes em termos de delineamento das informações desejadas. Dentre os critérios observados para a escolha dos artigos foram considerados os seguintes aspectos: disponibilidade do texto integral do estudo e clareza no detalhamento metodológico utilizado. Alguns livros considerados relevantes para este estudo foram adicionados.

Foram excluídos da amostra os artigos que não apresentavam relevância clínica sobre o tema abordado ou não relacionado ao assunto, bem como artigos não disponíveis e artigos duplicados.

RESULTADOS E DISCUSSÃO

\section{Lesões aos tecidos duros dentários e à polpa}

- Trinca de esmalte

Representa uma fratura incompleta em esmalte. Clinicamente apresenta ausência de sensibilidade à percussão. Se apresentar sensibilidade, avaliar quanto à possível ocorrência de lesão de luxação ou fratura radicular ${ }^{4}$.

Radiograficamente não há anormalidades, no entanto, se outros sinais ou sintomas forem observados podem ser realizadas radiografias para observar a presença de danos adicionais aos tecidos dentários. Nenhum tratamento é necessário. Apenas nos casos em que as trincas estão visíveis é que se recomenda a realização do condicionamento ácido e aplicação do sistema adesivo e o selamento com resina composta, podendo esta ser do tipo flow ${ }^{5}$.

Segundo recomendações da IADT, geralmente não é necessário realizar acompanhamento dessas lesões, a não ser que elas estejam associadas com lesões por luxações ou outros tipos de fraturas ${ }^{5}$.

- Fratura de esmalte e dentina sem exposição pulpar

Nesse tipo de lesão existe a perda de tecido dentário, podendo envolver apenas o esmalte ou esmalte e dentina sem exposição pulpar e pode ser acompanhado também de lesões no tecido de suporte ${ }^{6,7}$ Clinicamente é possível observar a perda de esmalte ou esmalte e dentina sem a presença de exposição pulpar. O dente acometido apresenta ausência de sensibilidade à percussão, mobilidade normal e resposta positiva aos testes de sensibilidade pulpar ${ }^{5}$.

É importante avaliar cuidadosamente 
como está a situação clínica para que o tratamento seja direcionado. Em alguns casos de fraturas apenas em esmalte, pode ser necessário apenas 0 alisamento das extremidades pontiagudas. Se 0 desgaste dentário deixar uma alteração estética notável, indica-se a realização da restauração em resina composta usando condicionamento ácido e sistemas adesivos ${ }^{7,8}$.

Para auxiliar na restauração de resina composta pode ser utilizada a matriz de poliéster ou pode ser realizado uma guia de referência onde é feita a moldagem com alginato para que o dente fraturado seja reconstruído em cera. Após isso, realiza-se uma moldagem com silicona de condensação e depois recorta a moldagem de modo a construir um anteparo palatino para auxiliar na inserção da resina composta com adequado contorno do dente fraturado ${ }^{6}$.

Se 0 fragmento dentário estiver disponível poderá ser realizada a colagem do fragmento ao dente. Esta colagem pode ser realizada tanto imediatamente após ou algum tempo depois do trauma. Em casos que a decisão for colar posteriormente é importante proteger a dentina exposta com fina camada de cimento de ionômero de vidro (CIV) ou algum outro material restaurador disponível. É importante manter o fragmento úmido em soro fisiológico antes de ser feita a colagem ${ }^{7}$.

A colagem de fragmento dental representa uma técnica relativamente simples e segura com excelente resultado estético e efeito positivo ao estado psicológico do paciente. Uma de suas limitações é a possibilidade de o fragmento descolar novamente, principalmente em um paciente com overbite acentuado, fratura extensa, bruxismo e hábitos nocivos como roer unhas e morder lápis ${ }^{9,10}$.

De acordo com Garcia et al. ${ }^{11}$ quanto aos materiais utilizados para colagem, diferentes estudos demonstram a utilização de diferentes tipos de materiais intermediários como a resina composta convencional, resina composta fluida, cimento resinoso ou cimento de ionômero de vidro. O protocolo clínico para colagem de fragmento dental com resina composta convencional está descrito no Quadro 1.

É importante realizar consultas de revisão para avaliar os aspectos clínicos e radiográficos dos dentes submetidos à técnica de colagem de fragmento. Realiza-se exames de vitalidade pulpar, sondagem periodontal, bem como a observação do aspecto estético da linha de união fragmento/remanescente. Se após vários meses de acompanhamento essa linha estiver interferindo na estética do paciente, deve-se considerar a possibilidade da realização de uma restauração com resina composta $^{10}$.

Quadro 1 - Protocolo clínico para colagem de fragmento dental com resina composta convencional

Sequência clínica para colagem de fragmento dental com resina composta

Armazenamento do fragmento dental em água/ soro fisiológico para reidratação;

Profilaxia (do fragmento e do dente)

Seleção do tipo de resina composta e da cor;

Verificar a adaptação do fragmento ao remanescente dental;

. Verificar a oclusão (máxima intercuspidação habitual, movimentos excursivos e

hábitos parafuncionais);

Anestesia

Isolamento do campo operatório;

Realização de preparo no remanescente e no fragmento dental (se necessário);

Limpeza do remanescente e do fragmento dental;

o. Condicionamento com ácido fosfórico a 37\% (30 segundos em esmalte e 15 segundos em dentina)

11. Aplicação do sistema adesivo (NÃO fotopolimerizar);

12. Inserção da resina composta no remanescente e no fragmento dental (fotopolimerizar)

13. Ajustes oclusais (se necessário)

14. Acabamento e polimento.

Fonte: Adaptação ${ }^{9,10,12}$

Em casos que o paciente procurar 0 profissional muito tempo após a lesão, é importante verificar a vitalidade pulpar e presença de lesão periapical, tendo em vista que, quando mais rápido a dentina que está exposta for protegida, melhores são as chances de manutenção da vitalidade pulpar ${ }^{6}$.

Segundo as Diretrizes da IADT para o manejo de lesões dentárias traumáticas, os casos em que os dentes apresentam respostas positivas aos testes de vitalidade pulpar são mais favoráveis. É necessário realizar o acompanhamento de até um ano para estas lesões ${ }^{5}$.

- Fratura de esmalte e dentina com exposição pulpar

Esse tipo de fratura envolve esmalte e dentina com exposição pulpar. Apresenta mobilidade dentária normal e ausência de sensibilidade à percussão, além disso, a polpa exposta pode ser sensível aos estímulos presentes na cavidade oral ${ }^{5}$.

Nesses casos, o objetivo principal do tratamento é manter a vitalidade pulpar. De forma geral, indica-se a realização do capeamento pulpar direto com hidróxido de cálcio ou agregado de trióxido de mineral (MTA). No entanto, para a realização deste procedimento alguns aspectos devem ser considerados e devem estar presentes para o melhor sucesso clínico possível, são eles: a exposição deve ser pequena, o paciente ser atendido logo após o traumatismo, não haver fratura radicular, o dente não ter sido deslocado e não haver nenhuma restauração profunda que possa indicar uma inflamação crônica da polpa ${ }^{8}$.

Para o capeamento pulpar deve-se realizar 0 isolamento absoluto seguido da aplicação do hidróxido de cálcio ou MTA na polpa exposta. Depois da realização do capeamento pulpar é necessário avaliar qual a melhor alternativa de restauração a ser realizada, se será feita uma restauração 
definitiva ou provisória. A restauração definitiva poderá ser feita por meio da colagem do fragmento, resinas compostas e até mesmo de forma indireta à exemplo de cerâmicas ${ }^{9}$.

É importante que a superfície dentinária exposta seja descontaminada e uma adequada hemostasia seja realizada para que se aumente as chances de sucesso do tratamento. Os agentes de capeamento pulpar nunca devem ser aplicados em uma polpa que ainda esteja sangrando ou apresente coágulo clinicamente visível $^{9}$.

Nos casos em que a exposição aconteceu em um período prolongado e o paciente demorou muito tempo para procurar atendimento, o tratamento dependerá das condições de desenvolvimento radicular. Sendo assim, é proposto pelos autores classificar os dentes permanentes com fraturas de esmalte e dentina com exposição pulpar em dentes com rizogênese completa ou incompleta ${ }^{6}$.

Em dentes que apresentam vitalidade pulpar e rizogênese incompleta a terapia indicada é a pulpotomia. Esta terapia consiste na remoção asséptica parcial polpa coronária infectada com a conservação da polpa radicular. Com o auxílio de uma broca esférica diamantada em alta rotação, remove-se cerca de $3 \mathrm{~mm}$ do tecido pulpar exposto, aplica-se medicação à base de corticosteróide por 5 minutos, lavagem do tecido, coloca-se a pasta de hidróxido de cálcio, insere-se o cimento de hidróxido de cálcio, introduzir o CIV, realiza-se o condicionamento ácido, aplica-se o sistema adesivo e por fim realiza-se a restauração com resina composta. Contudo, esta é uma medida provisória para manter a vitalidade pulpar até 0 completo fechamento do ápice radicular. Posteriormente, a terapia endodôntica deve ser instituída ${ }^{6,8}$.

Em dentes com vitalidade pulpar e rizogênese completa com grande exposição de tecido pulpar, indica-se a realização do tratamento endodôntico completo $^{13}$. Ainda, de acordo com Miloro et al. ${ }^{14}$ além do estágio de desenvolvimento radicular, outro aspecto a ser considerado na decisão de instituir o tratamento endodôntico ou não é o tempo em que o paciente é visto após a exposição pulpar. Se o paciente é visto em menos de $24 \mathrm{~h}$ é possível realizar apenas o capeamento pulpar, após $24 \mathrm{~h}$ o tratamento endodôntico deve ser instituído.

O tratamento da coroa fraturada pode ser realizado também através da colagem do fragmento dental se ele estiver disponível, como descrito acima para os casos de fraturas da coroa sem exposição pulpar. Como também, pode ser feita a restauração com resina composta por meio das técnicas também descritas acima. É importante realizar o acompanhamento clínico e radiográfico de até 1 ano de dentes com essas lesões ${ }^{5}$.

- Fratura coronorradicular

As fraturas coronorradiculares envolvem esmalte, dentina e cemento e correspondem à uma pequena porcentagem das lesões traumáticas dentárias (cerca de $5 \%$ das lesões aos dentes permanentes e $2 \%$ aos dentes decíduos). Essas lesões podem classificar-se em: sem complicação (onde há acometimento do esmalte, dentina e raiz sem exposição pulpar) e com complicação (onde além do acometimento das estruturas dentais e radiculares há exposição pulpar) $)^{7,13}$.

Clinicamente pode ser observado dor à percussão, mobilidade do fragmento coronário e o teste de sensibilidade pulpar positivo para o fragmento apical. Radiograficamente é importante verificar a presença e posição das linhas de fraturas na porção radicular ${ }^{5}$.

O tratamento imediato consiste em realizar a estabilização do fragmento coronário para posterior avaliação da conduta mais adequada a ser seguida. A localização do segmento de fratura, morfologia da lesão, morfologia da raiz e posicionamento na arcada dentária do elemento traumatizado determina o tipo de conduta terapêutica a ser seguida ${ }^{8,13}$.

Nas fraturas não complicadas (sem exposição pulpar) em que a linha de fratura está acima ou ligeiramente abaixo da margem cervical, o dente é passível de restauração. Entretanto, se a fratura converge excessivamente para o sentido apical pode ser indicada a exodontia com posterior reabilitação através de implantes ou prótese fixa convencional $^{8}$. Nas fraturas complicadas (com envolvimento pulpar) o nível de fratura radicular determina o tratamento. Se a fratura inclui mais de um terço da raiz ou em casos de fraturas radiculares verticais, é indicada a exodontia. Caso contrário, o dente pode ser tratado endodonticamente e depois restaurado ${ }^{8}$.

Uma alternativa consiste na restauração do dente com pino e coroa. Para isso, deve-se remover o fragmento coronário, em seguida realiza-se 0 tratamento endodôntico do fragmento remanescente. Diversos procedimentos podem ser realizados para auxiliar na execução desta alternativa de tratamento como cirurgias periodontais através da gengivectomia e gengivoplastia, extrusão ortodôntica e extrusão cirúrgica do fragmento apical com tamanho suficiente para suportar a posterior restauração com pino e coroa ${ }^{5}$.

Segundo as diretrizes da IADT para o 
tratamento de fraturas coronorradiculares com envolvimento pulpar, é importante considerar o nível de desenvolvimento radicular. Sendo assim, em pacientes com rizogênese incompleta é vantajoso preservar a vitalidade pulpar por meio da realização de uma pulpotomia parcial ao invés de instituir o tratamento endodôntico direto que é o tratamento de escolha em pacientes com rizogênese completa. $O$ acompanhamento clínico e radiográfico por um período de 6-8 semanas e posteriormente 1 ano deve ser instituído ${ }^{5}$.

\section{- Fraturas radiculares}

As fraturas radiculares são lesões incomuns e correspondem a cerca de $6 \%$ dos traumatismos dentários e são caracterizadas por fraturas horizontais, verticais ou oblíquas que envolvem dentina, cemento e polpa. Os dentes mais acometidos são os incisivos superiores (65\%), em $45 \%$ dos casos de fraturas radiculares dentes adicionais também são acometidos e $40 \%$ está associado à fratura alveolar ${ }^{13}$.

São comumente chamadas de fraturas horizontais e podem ser divididas na localização do fragmento em fraturas do terço cervical, médio e apical. As fraturas do terço médio são relativamente mais comuns e podem ser únicas ou múltiplas ${ }^{15}$.

Clinicamente o dente pode apresentar mobilidade, pode estar deslocado, ligeiramente extruído e sensível à percussão sendo, muitas vezes, difícil a distinção clínica da fratura radicular com lesões por luxação ${ }^{7}$. Pode ser observado, ainda, sangramento através do sulco gengival e o teste de sensibilidade pulpar pode ser negativo inicialmente, indicando dano neural transitório ou permanente. Por esse motivo, recomenda-se o monitoramento da condição pulpar ${ }^{5}$.

Uma simples radiografia pode não ser suficiente para demonstrar uma fratura radicular. Dessa forma, várias incidências com angulações diferentes podem ser necessárias. Para que se consiga observar uma fratura de raiz na radiografia, o feixe central dos raios $X$ deve ser paralelo à linha de fratura; se o feixe incidir de forma oblíqua uma imagem com duas ou mais linhas de fraturas ou até mesmo a não visualização da fratura pode acontecer ${ }^{6,8}$.

Radiografias oclusais são ideais para localizar fraturas no terço apical das raízes quando o plano de fratura é oblíquo ${ }^{13}$. Além do mais, também é possível utilizar métodos tridimensionais como a TCFC que permite uma visualização mais precisa e elimina a sobreposição de estruturas ${ }^{16}$.
No tratamento das fraturas radiculares um dos principais aspectos a serem considerados é a posição da fratura com relação à margem gengival. Fraturas localizadas entre o terço médio e apical da raiz possuem melhor prognóstico quanto à sobrevivência da polpa e cicatrização dos fragmentos entre si quando comparada às fraturas localizadas próximo ao terço cervical. Isso acontece, principalmente, em virtude da comunicação do terço coronal da raiz com a cavidade oral e a subsequente contaminação microbiana da polpa ocasionando a necrose pulpar ${ }^{17}$.

Em dentes que a fratura ocorreu próxima à margem cervical e 0 dente apresenta mobilidade significativa, os fragmentos apical e coronário podem ser removidos, ou então, pode-se remover apenas a porção coronária, realizar o tratamento endodôntico no fragmento remanescente e finalizar com uma restauração com pino, núcleo e coroa. Além disso, é possível realizar também a extrusão ortodôntica ou cirúrgica dos fragmentos apicais remanescentes com o objetivo de nivelar a coroa com os dentes adjacentes. Já nas fraturas do terço médio e apical, muitas vezes, os fragmentos cicatrizam sem a necessidade de terapia endodôntica, realizando-se apenas a esplintagem ${ }^{13}$.

O tratamento endodôntico não deve ser realizado na fase de emergência, tendo em vista que o tecido pulpar ainda é passível de reparação. No entanto, se ainda sim a necrose pulpar se desenvolver realiza-se o tratamento endodôntico do segmento radicular fraturado ${ }^{7}$.

Segundo diretrizes da IADT a contenção flexível das fraturas radiculares do terço apical e médio deve ser realizada por um período de 4 semanas. Já em fraturas localizadas acima ou perto da margem gengival indica-se uma contenção por até 4 meses. Em casos de fraturas radiculares verticais a exodontia é indicada tanto para dentes decíduos quanto para os dentes permanentes ${ }^{5,13}$.

Após a estabilização, é importante examinar e ajustar adequadamente a oclusão para evitar forças mastigatórias excessivas no dente afetado. Além do mais, o acompanhamento e controle radiográfico devem ser realizados em consultas posteriores para a cicatrização dos tecidos pulpares e periapicais $^{13}$.

As complicações que podem surgir após fraturas radiculares incluem: obliteração e calcificação do canal pulpar, reabsorção radicular interna e externa e necrose pulpar ${ }^{13}$.

É recomendado pelas diretrizes da IADT monitorar a vitalidade pulpar por pelo menos 1 
ano. Além disso, acompanhamento clínico e radiográfico nas primeiras 4 semanas seguidas, 4 meses, 6 meses e anual em até 5 anos deve ser instituído ${ }^{5}$.

\section{Fraturas do processo alveolar}

As lesões ao processo alveolar são lesões pouco frequentes e representam menos de $3 \%$ de todas as lesões traumáticas; acometem com mais frequência pacientes jovens do sexo masculino ${ }^{18}$.

São frequentemente acompanhadas por traumatismos dentários. De forma que, fraturas coronárias, radiculares ou lesões aos tecidos moles ocorrem, na maioria das vezes, concomitantemente às fraturas alveolares ${ }^{8}$. Um dos sinais típicos que podem indicar fratura alveolar é quando testamos a mobilidade de apenas um dente e os outros adjacentes também se movimentam. ${ }^{7}$

Em um estudo realizado por Andreasen e Lauridsen ${ }^{18}$ foi possível observar que as fraturas do processo alveolar foram frequentemente vistas em pacientes que sofreram lesões por chutes no rosto, ou em casos de colisão com outras pessoas ou objetos.

O tratamento é bastante difícil e pode requerer cirurgias para o reposicionamento do segmento fraturado sendo muitas vezes mais bem tratadas se forem encaminhadas ao cirurgião bucomaxilofacial ${ }^{8}$.

Inicialmente, realiza-se a redução da fratura para que o osso alveolar volte à sua posição original. A redução é feita por meio da pressão manual; se houver cominuição e exposição do osso subjacente, pode ser realizada a redução aberta ${ }^{19}$.

A técnica de redução fechada consiste em pressionar a parte apical da unidade de dentes/osso fraturado com um dedo de uma mão e outro dedo é colocado na superfície incisiva ou oclusal dos dentes. A pressão é realizada para baixo de forma que o fragmento deslocado seja assentado verticalmente ${ }^{19}$.

Após a adequada redução, é feita fixação rígida e o segmento fraturado deve ser estabilizado por aproximadamente 4 semanas até que ocorra a completa cicatrização óssea ${ }^{20}$.

\section{Estabilização dos traumatismos dento- alveolares}

Segundo Prado e Salim ${ }^{21}$ os primeiros relatos de estabilização dentária surgiram em 1930, quando Wigopen descreveu uma técnica de contenção com gesso de um dente avulsionado durante 8 meses. A contenção é responsável por conferir estabilidade aos dentes traumatizados e restringe os danos à polpa e aos tecidos periodontais fornecendo condições adequadas de cicatrização durante o período de regeneração ${ }^{13}$.

É importante que a estabilização possibilite movimentos fisiológicos do dente e permaneça apenas o tempo necessário à regeneração tecidual para prevenir e diminuir os processos de anquilose ${ }^{13}$.

Sendo assim, é desejável que a estabilização dentária apresente as seguintes características: ser realizada diretamente no paciente sem a necessidade de processos laboratoriais, ser de fácil remoção, não causar danos aos tecidos moles, ter estética aceitável, não interferir na oclusão, possibilitar movimentos fisiológicos do dente, possibilitar boa higienização, permitir procedimentos endodônticos quando for necessário ${ }^{13}$.

Diversas técnicas contenção estão disponíveis, no entanto, as técnicas com resina composta e ácido fosfórico $(36,5 \%)$ demonstram ser um método versátil, relativamente simples e eficazes em todos os tipos de TDA e são as mais comumente utilizadas ${ }^{7}$.

Para contenção com ácido fosfórico e resina composta podem ser utilizados os fios de aço de fabricação padrão (calibre 26), fio de náilon ou clipes de papel. Recomenda-se o emprego de resinas composta com cor diferente da cor natural do dente para facilitar a remoção e evitar o trauma ao esmalte ${ }^{14} \mathrm{O}$ protocolo clínico indicado para este tipo de contenção encontra-se descrito no Quadro 2.

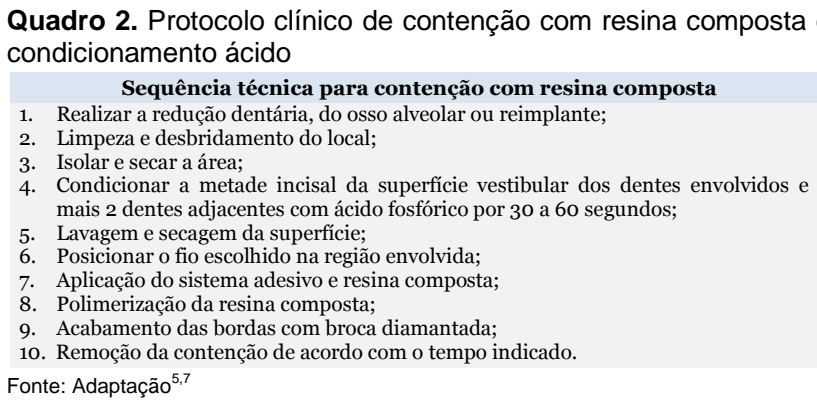

O tempo de estabilização pode variar de acordo com o tipo de lesão. A Tabela 1 exemplifica os tipos de contenção e período de imobilização para os tipos de TDA que necessitam de fixação.

Verificou-se na literatura, um aspecto importante e que apresenta bastante divergência entre os autores, no que se refere ao período e tipo (flexível ou rígida) de estabilização para as lesões dento-alveolares. No entanto, de acordo com Fonseca ${ }^{13}$ estudos demonstraram que o período de duração da imobilização não possui associação com a cicatrização pós-trauma e não gera sequelas negativas. Dessa forma, parece depender bastante da situação clínica apresentada. 
Portanto, este não é o fator mais importante na abordagem em traumatismo dento-alveolares.

Tabela 1. Protocolo clínico de contenção com resina composta e condicionamento ácido.

\begin{tabular}{|c|c|c|}
\hline Lesão & Tipo de Contenção & Período de estabilização \\
\hline Subluxação & Flexível & 2 semanas \\
\hline Luxação extrusiva & Flexível & 2 semanas \\
\hline Luxação lateral & Flexível & 4 semanas \\
\hline Intrusão & Flexível & 4-8 semanas \\
\hline Avulsão & Flexível & 2 semanas \\
\hline Fratura de raiz (terço cervical) & Flexível & 4 meses \\
\hline Fratura de raiz (terço apical e médio) & Flexível & 4 semanas \\
\hline Fratura do processo alveolar & Rígida & 4 semanas \\
\hline $\begin{array}{l}\text { Lesão } \\
\text { Subluxacão }\end{array}$ & de Contenção & Período de estabilização \\
\hline Subluxação & Flexível & 2 semanas \\
\hline Luxação extrusiva & Flexível & 2 semanas \\
\hline Luxação lateral & Flexi & 4 semanas \\
\hline Intrusão & Flexível & 4-8 semanas \\
\hline Avulsão & Flexível & 2 semanas \\
\hline Fratura de raiz (terço cervical) & Flexível & 4 meses \\
\hline Fratura de raiz (terço apical e médio) & Flexível & 4 semanas \\
\hline Fratura do processo alveolar & Rígida & 4 semanas \\
\hline Lesão & Tipo de Contenção & Período de estabilização \\
\hline Subluxação & Flexível & 2 semanas \\
\hline Luxação extrusiva & Flexível & 2 semanas \\
\hline Luxação lateral & Flexí & 4 semanas \\
\hline Intrusão & Flexív & 4-8 semanas \\
\hline Avulsão & Flexível & 2 semanas \\
\hline Fratura de raiz (terço cervical) & Flexível & 4 meses \\
\hline Fratura de raiz (terço apical e médio) & Flexível & 4 semanas \\
\hline Fratura do processo alveolar & Rígida & 4 semanas \\
\hline
\end{tabular}

CONCLUSÃO

As fraturas aos tecidos duros dentários e da polpa são as mais comumente encontradas dentro todas as lesões por traumatismo dentoalveolares. Os casos em que além da fratura da coroa e/ou raiz existe o envolvimento pulpar são considerados mais complexos, principalmente no que concerne ao tratamento correto das lesões. Por esse motivo, é importante que o profissional realize um adequado diagnóstico bem como o correto acompanhamento dessas lesões.

\section{REFERÊNCIAS}

1. Cavallli MA, Oliveira BO, Nuernberger PVF, Cristófaro M, Cadioli IC, Wanderley MT. Colagem de dente permanente com fratura sem exposição pulpar. Clin lab res dent. 2014;20(2):110-16.

2. Gerard LN, Martos J, Baldisserra RA, Lund RG. Reabilitação estética em dente anterior com extensa fratura coronária: relato de caso. Rev Fac Odontol Lins. 2014;24(1):58-63.

3. Traebert J, Claudino D. Epidemiologia do Traumatismo Dentário em Crianças: A Produção Científica Brasileira. Pesqui Bras Odontopediatria Clín Integr. 2012;12(2):263-72.

4. Malmgren B, Andreasen JO, Flores MT, Robertson A, Diangelis AJ, Andersson I, et al. International Association of Dental Traumatology guidelines for the management of traumatic dental injuries: 3 . Injuries in the primary dentition. Dent Traumatol. 2012;28(3):174-82.

5. Diangelis AJ, Andreasen JO, Ebeleseder KA, Kenny DJ, Trope $M$, Sigurdsson $A$ et al. International Association of Dental Traumatology guidelines for the management of traumatic dental injuries: 1. Fractures and luxations of permanent teeth. Dent Traumatol. 2012;28(3):2-12.

6. Guedes Pinto AC. Odontopediatria. 9ed. São Paulo: Santos; 2016.

7. Pogrel MA, Kahnberg KE, Anderson L. Cirurgia bucomaxilofacial. Rio de Janeiro: Santos; 2016.

8. Hupp JR, Ellis III E, Tucker MR. Cirurgia oral e maxilofacial contemporânea. 5ed. Elsevier: Rio de Janeiro; 2015.

9. Baratieri LN, Monteiro Jr S. et al. Odontologia Restauradora - Fundamentos e Possibilidades. 2ed. São Paulo: Santos; 2015.

10. Conceição EN. Dentística Saúde e Estética. 2ed. Porto Alegre: Artmed, 2007.

11. Garcia FCP, Poubel DLN, Almeida JCF, Toledo IP, Poi WR. et al. Tooth fragment reattachment techniques-A systematic review. Dent Traumatol. 2018;34(3):135-43.

12. Baratieri LN, Monteiro Jr S, Melo TS. et al. Odontologia Restauradora: fundamentos e técnicas, volume 1. São Paulo: Santos, 2013.

13. Fonseca RJ, Walker RV, Barber HD, Powers MP, Frost DE. Trauma Bucomaxilofacial. 4ed. Rio de Janeiro: Elsevier; 2015.

14. Miloro M, Ghali GE, Larsen PE, Waite PD. Princípios de cirurgia bucomaxilofacial de Peterson. 3ed. São Paulo: Santos; 2016.

15. Rangareddy MS, Daga A, Vardhan VV, Daneswari M. Management of Root Fracture: A Novel, Noninvasive Treatment Approac. Case Rep Dent. 2013; 653261.

16. Kobayashi-Velasco S, Salineiro FCV, Gialain JO, Cavalcanti MGP. Diagnosis of alveolar and root fractures: an in vitro study comparing CBCT imaging with periapical radiographs. J App Oral Sci. 2017;25(2):227-33.

17. Cantore S, Ballini A, CRincoli V, Grassi FR. Treatment of horizontal root fracture: a case report. Cases J. 2009;2:8101.

18. Andreasen JO, Lauridsen E. Alveolar process fractures in the permanent dentition. Part 1. Etiology and clinical characteristics. A retrospective analysis of 299 cases involving 815 teeth. Dent Traumatol. 2015;31(6):442-47.

19. Lim L, Sirichai P. Bone fractures: assessment and management. Aust Dent J. 2016;61(supl. 1):74-81.

20. Macleod SP, Rudd TC. Update on the management of dentoalveolar trauma. Curr Opin Otolaryngol Head Neck Surg. 2012;20(4):318-24.

21. Prado R, Salim M. Cirurgia bucomaxilofacial: diagnóstico e tratamento. 2ed. Rio de Janeiro: Guanabara Koogan; 2018. 


\section{CONFLITO DE INTERESSES}

Os autores declaram não haver conflitos de interesse

\section{AUTOR PARA CORRESPONDÊNCIA}

Rodrigo Gadelha Vasconcelos

Universidade Estadual da Paraíba

Av. Coronel Pedro Targino,

58233-000 Araruna-PB, Brasil

Tel: (83) 3373-1040

e-mail: rodrigogadelhavasconcelos@yahoo.com.br

Submetido em 20/03/2021

Aceito em 04/11/2021 